\title{
A Study on (Q,L)-Fuzzy Normal Subsemiring of a Semiring
}

\author{
S. Sampathu ${ }^{1}$, S. Anita Shanthi ${ }^{2}$, A. Praveen Prakash ${ }^{3}$ \\ ${ }^{1}$ Department of Mathematics, Sri Muthukumaran College of Education, Chikkarayapuram, Chennai, Tamil Nadu, India \\ ${ }^{2}$ Department of Mathematics, Annamalai University, Tamil Nadu, India \\ ${ }^{3}$ Department of Mathematics, Hindustan University, Padur, Tamil Nadu, India
}

\section{Email address:}

sampathugokul@yahoo.in (S. Sampathu), shanthi.Anita@yahoo.com (S. A. Shanthi), apraveenprakash@gmail.com (A. P. Prakash)

\section{To cite this article:}

S. Sampathu, S. Anita Shanthi, A. Praveen Prakash. A Study on (Q,L)-Fuzzy Normal Subsemiring of a Semiring. American Journal of Applied Mathematics. Vol. 3, No. 4, 2015, pp. 185-188. doi: 10.11648/j.ajam.20150304.14

\begin{abstract}
In this paper, we introduce the concept of (Q,L)-fuzzy normal subsemirings of a semiring and establish some results on these. We also made an attempt to study the properties of $(\mathrm{Q}, \mathrm{L})$-fuzzy normal subsemirings of semiring under homomorphism and anti-homomorphism, and study the main theorem for this. We shall also give new results on this subject.
\end{abstract}

Keywords: (Q,L)-Fuzzy Subset, (Q,L)-Fuzzy Subsemiring, (Q,L)-Fuzzy Normal Subsemiring, Product Of (Q,L)-Fuzzy Subsets, Strongest (Q, L)-Fuzzy Relation, Pseudo (Q, L)-Fuzzy Coset

\section{Introduction}

There are many concepts of universal algebras generalizing an associative ring $(\mathrm{R} ;+;$. . ). Some of them in particular, nearrings and several kinds of semirings have been proven very useful. An algebra $(\mathrm{R} ;+,$.$) is said to be a semiring if (\mathrm{R} ;+)$ and $(\mathrm{R} ;$.) are semigroups satisfying $\mathrm{a} .(\mathrm{b}+\mathrm{c})=\mathrm{a} . \mathrm{b}+\mathrm{a} . \mathrm{c}$ and $(b+c) . a=b . a+c . a$ for all $a, b$ and $c$ in $R$. A semiring $R$ is said to be additively commutative if $a+b=b+a$ for all $a, b$ in $R$. A semiring $\mathrm{R}$ may have an identity 1 , defined by $1 . \mathrm{a}=\mathrm{a}=\mathrm{a} .1$ and a zero 0 , defined by $0+a=a=a+0$ and $a \cdot 0=0=0$. for all $\mathrm{a}$ in R. After the introduction of fuzzy sets by L.A.Zadeh[15], several researchers explored on the generalization of the concept of fuzzy sets. The notion of fuzzy subnearrings and ideals was introduced by S.Abou Zaid[10]. A.Solairaju and R.Nagarajan [12] have introduced and defined a new algebraic structure called Q-fuzzy subgroups. In this paper, we introduce the concept of (Q,L)-fuzzy normal subsemiring of a semiring and established some results.

\section{Preliminaries}

\subsection{Definition 1}

Let $\mathrm{X}$ be a non-empty set and $\mathrm{L}=(\mathrm{L}, \leq)$ be a lattice with least element 0 and greatest element 1 and $\mathrm{Q}$ be a non-empty set. $A(Q, L)$-fuzzy subset $A$ of $X$ is a function $A: X \times Q \rightarrow L$.

\subsection{Definition 2}

Let $(\mathrm{R},+, \cdot)$ be a semiring and $\mathrm{Q}$ be a non empty set. A $(\mathrm{Q}$, $\mathrm{L}$ )-fuzzy subset $\mathrm{A}$ of $\mathrm{R}$ is said to be $\mathrm{a}(\mathrm{Q}, \mathrm{L})$-fuzzy subsemiring (QLFSSR) of $\mathrm{R}$ if the following conditions are satisfied:

(i) $A(x+y, q) \geq A(x, q) \wedge A(y, q)$, Q.

(ii) $A(x y, q) \geq A(x, q) \wedge A(y, q)$, for all $x$ and $y$ in $R$ and $q$ in

\subsection{Definition 3}

Let $\mathrm{R}$ be a semiring and $\mathrm{Q}$ be a non-empty set. An (Q, L)-fuzzy subsemiring $A$ of $R$ is said to be an (Q, L)-fuzzy normal subsemiring (QLFNSSR) of $\mathrm{R}$ if it satisfies the following conditions:

(i) $\mathrm{A}(\mathrm{x}+\mathrm{y}, \mathrm{q})=\mathrm{A}(\mathrm{y}+\mathrm{x}, \mathrm{q})$,

(ii) $A(x y, q)=A(y x, q)$, for all $x$ and $y$ in $R$ and $q$ in $Q$.

\subsection{Definition 4}

Let $A$ and $B$ be any two (Q,L)-fuzzy subsets of sets $G$ and $H$, respectively. The product of $A$ and $B$, denoted by $A \times B$, is defined as $A \times B=\{<((x, y), q), A \times B((x, y), q)>/$ for all $x$ in $R$ and $y$ in $H$ and $q$ in $Q$, where $A \times B((x, y), q)=A(x, q) \wedge B(y, q)$.

\subsection{Definition 5}

Let $(\mathrm{R},+, \cdot)$ and $\left(\mathrm{R}^{\prime},+, \cdot\right)$ be any two semirings and $\mathrm{Q}$ be a non empty set. Let $f: R \rightarrow R^{\prime}$ be any function and $A$ be a (Q,L)-fuzzy subsemiring in $\mathrm{R}, \mathrm{V}$ be a (Q,L)-fuzzy subsemiring in $\mathrm{f}(\mathrm{R})=\mathrm{R}^{\prime}$, defined by $\mathrm{V}(\mathrm{y}, \mathrm{q})=\sup \mathrm{A}(\mathrm{x}, \mathrm{q})$, for 
all $\mathrm{x}$ in $\mathrm{R}$ and $\mathrm{y}$ in $\mathrm{R}$ 'and $\mathrm{q}$ in $\mathrm{Q}$. Then $\mathrm{A}$ is called a pre-image of $\mathrm{V}$ under $\mathrm{f}$ and is denoted by $\mathrm{f}^{-1}(\mathrm{~V})$.

\subsection{Definition 6}

Let $A$ be a $(\mathrm{Q}, \mathrm{L})$-fuzzy subset in a set $\mathrm{S}$, the strongest $(\mathrm{Q}$, $\mathrm{L})$-fuzzy relation on $\mathrm{S}$, that is a $(\mathrm{Q}, \mathrm{L})$-fuzzy relation $\mathrm{V}$ with respect to $A$ given by $\mathrm{V}((\mathrm{x}, \mathrm{y}), \mathrm{q})=\mathrm{A}(\mathrm{x}, \mathrm{q}) \wedge \mathrm{A}(\mathrm{y}, \mathrm{q})$, for all $\mathrm{x}$ and $\mathrm{y}$ in $\mathrm{S}$ and $\mathrm{q}$ in $\mathrm{Q}$.

\subsection{Definition 7}

$A(Q, L)$-fuzzy subset $A$ of a set $X$ is said to be normalized if there exists an element $x$ in $X$ such that $A(x, q)=1$.

\subsection{Definition 8}

Let $\mathrm{A}$ be an $(\mathrm{Q}, \mathrm{L})$-fuzzy subsemiring of a semiring $(\mathrm{R},+, \cdot)$ and $\mathrm{a}$ in $\mathrm{R}$. Then the pseudo $(\mathrm{Q}, \mathrm{L})$-fuzzy coset $(\mathrm{aA})^{\mathrm{p}}$ is defined by $\left((a A)^{p}\right)(x, q)=p(a) A(x, q)$, for every $x$ in $R$ and for some $\mathrm{p}$ in $\mathrm{P}$ and $\mathrm{q}$ in $\mathrm{Q}$.

\subsection{Definition 9}

Let $A$ be a $(\mathrm{Q}, \mathrm{L})$-fuzzy subset of $\mathrm{X}$. For $\alpha$ in $\mathrm{L}$, a Q-level subset of $A$ is the set $A_{\alpha}=\{x \in X: A(x, q) \geq \alpha\}$.

\section{Properties of $(\mathrm{Q}, \mathrm{L})$-Fuzzy Normal Subsemiring of a Semiring}

\subsection{Theorem 1}

Let $(\mathrm{R},+,$.$) be a semiring and \mathrm{Q}$ be a non-empty set. If $\mathrm{A}$ and $B$ are two $(\mathrm{Q}, \mathrm{L})$-fuzzy normal subsemirings of $\mathrm{R}$, then their intersection $A \cap B$ is an $(Q, L)$-fuzzy normal subsemiring of $R$.

Proof: Let $x$ and $y \in R$. Let $A=\{\langle(x, q), A(x, q)\rangle / x$ in $R$ and $q$ in $\mathrm{Q}\}$ and $\mathrm{B}=\{\langle(\mathrm{x}, \mathrm{q}), \mathrm{B}(\mathrm{x}, \mathrm{q})\rangle / \mathrm{x}$ in $\mathrm{R}$ and $\mathrm{q}$ in $\mathrm{Q}\}$ be (Q,L)-fuzzy normal subsemirings of a semiring $\mathrm{R}$. Let $\mathrm{C}=\mathrm{A} \cap \mathrm{B}$ and $\mathrm{C}=\{\langle(\mathrm{x}, \mathrm{q}), \mathrm{C}(\mathrm{x}, \mathrm{q})\rangle / \mathrm{x}$ in $\mathrm{R}$ and $\mathrm{q}$ in $\mathrm{Q}\}$. Then, Clearly $C$ is an $(\mathrm{Q}, \mathrm{L})$-fuzzy subsemiring of a semiring $\mathrm{R}$, since $A$ and $B$ are two $(Q, L)$-fuzzy subsemirings of a semiring $R$. And (i) $\mathrm{C}(\mathrm{x}+\mathrm{y}, \mathrm{q})=\mathrm{A}(\mathrm{x}+\mathrm{y}, \mathrm{q}) \wedge \mathrm{B}(\mathrm{x}+\mathrm{y}, \mathrm{q})=\mathrm{A}(\mathrm{y}+\mathrm{x}, \mathrm{q}) \wedge \mathrm{B}(\mathrm{y}+\mathrm{x}, \mathrm{q})$ $=\mathrm{C}(\mathrm{y}+\mathrm{x}, \mathrm{q})$, for all $\mathrm{x}$ and $\mathrm{y}$ in $\mathrm{R}$ and $\mathrm{q}$ in $\mathrm{Q}$. Therefore, $\mathrm{C}(\mathrm{x}+\mathrm{y}, \mathrm{q})=(\mathrm{y}+\mathrm{x}, \mathrm{q})$, for all $\mathrm{x}$ and $\mathrm{y}$ in $\mathrm{R}$ and $\mathrm{q}$ in $\mathrm{Q}$. (ii) $\mathrm{C}(\mathrm{xy}, \mathrm{q})=\mathrm{A}(\mathrm{xy}, \mathrm{q}) \wedge \mathrm{B}(\mathrm{xy}, \mathrm{q})=\mathrm{A}(\mathrm{yx}, \mathrm{q}) \wedge \mathrm{B}(\mathrm{yx}, \mathrm{q})=\mathrm{C}(\mathrm{yx}, \mathrm{q})$, for all $x$ and $y$ in $R$ and $q$ in $Q$. Therefore, $C(x y, q)=C(y x, q)$, for all $\mathrm{x}$ and $\mathrm{y}$ in $\mathrm{R}$ and $\mathrm{q}$ in $\mathrm{Q}$. Hence $\mathrm{A} \cap \mathrm{B}$ is an $(\mathrm{Q}, \mathrm{L})$-fuzzy normal subsemiring of a semiring $\mathrm{R}$.

\subsection{Theorem 2}

Let $\mathrm{R}$ be a semiring and $\mathrm{Q}$ be a non-empty set. The intersection of a family of (Q,L)-fuzzy normal subsemirings of $\mathrm{R}$ is an (Q,L)-fuzzy normal subsemiring of $\mathrm{R}$.

Proof: Let $\left\{\mathrm{A}_{\mathrm{i}}\right\}_{\mathrm{i} \in \mathrm{I}}$ be a family of (Q,L)-fuzzy normal subsemirings of a semiring $\mathrm{R}$ and let $\mathrm{A}=\bigcap_{i \in I} A_{i}$. Then for $\mathrm{x}$ and $\mathrm{y}$ in $\mathrm{R}$ and $\mathrm{q}$ in $\mathrm{Q}$. Clearly the intersection of a family of $(\mathrm{Q}, \mathrm{L})$-fuzzy subsemirings of a semiring $\mathrm{R}$ is an $(\mathrm{Q}, \mathrm{L})$-fuzzy subsemiring of a semiring R.(i) $\mathrm{A}(\mathrm{x}+\mathrm{y}, \mathrm{q})=\inf _{x \in f^{-1}(y)} \mathrm{A}_{\mathrm{i}}(\mathrm{x}+\mathrm{y}, \mathrm{q})=$ $\inf _{x \in f^{-1}(y)} \mathrm{A}_{\mathrm{i}}(\mathrm{y}+\mathrm{x}, \mathrm{q})=\mathrm{A}(\mathrm{y}+\mathrm{x}, \mathrm{q})$. Therefore, $\mathrm{A}(\mathrm{x}+\mathrm{y}, \mathrm{q})=\mathrm{A}(\mathrm{y}+\mathrm{x}, \mathrm{q})$, for all $\mathrm{x}$ and $\mathrm{y}$ in $\mathrm{R}$ and $\mathrm{q}$ in $\mathrm{Q}$. (ii) $\mathrm{A}(\mathrm{xy}, \mathrm{q})=\inf _{x \in f^{-1}(y)} \mathrm{A}_{\mathrm{i}}(\mathrm{xy}, \mathrm{q})=$ $\inf _{f^{-1}(y)} \mathrm{A}_{\mathrm{i}}(\mathrm{yx}, \mathrm{q})=\mathrm{A}(\mathrm{yx}, \mathrm{q})$. Therefore, $\mathrm{A}(\mathrm{xy}, \mathrm{q})=\mathrm{A}(\mathrm{yx}, \mathrm{q})$, for all $\mathrm{x}$ and $\mathrm{y}$ in $\mathrm{R}$ and $\mathrm{q}$ in Q.Hence the intersection of a family of (Q,L)-fuzzy normal subsemirings of a semiring $\mathrm{R}$ is an (Q,L)-fuzzy normal subsemiring of a semiring $\mathrm{R}$.

\subsection{Theorem 3}

Let $A$ and $B$ be (Q,L)-fuzzy subsemiring of the semirings $G$ and $\mathrm{H}$, respectively. If $\mathrm{A}$ and $\mathrm{B}$ are $(\mathrm{Q}, \mathrm{L})$-fuzzy normal subsemirings, then $\mathrm{A} \times \mathrm{B}$ is an $(\mathrm{Q}, \mathrm{L})-$ fuzzy normal subsemiring of $\mathrm{G} \times \mathrm{H}$.

Proof: Let A and B be (Q,L)-fuzzy normal subsemirings of the semirings $G$ and $H$ respectively. Clearly $A \times B$ is an $(\mathrm{Q}, \mathrm{L})$-fuzzy subsemiring of $\mathrm{G} \times \mathrm{H}$. Let $\mathrm{x}_{1}$ and $\mathrm{x}_{2}$ be in $\mathrm{G}, \mathrm{y}_{1}$ and $\mathrm{y}_{2}$ be in $\mathrm{H}$ and $\mathrm{q}$ in $\mathrm{Q}$. Then $\left(\mathrm{x}_{1}, \mathrm{y}_{1}\right)$ and $\left(\mathrm{x}_{2}, \mathrm{y}_{2}\right)$ are in $\mathrm{G} \times \mathrm{H}$. Now, $A \times B\left[\left(x_{1}, y_{1}\right)+\left(x_{2}, y_{2}\right), q\right]=A \times B\left(\left(x_{1}+x_{2}, y_{1}+y_{2}\right), q\right)$

$=\mathrm{A}\left(\mathrm{x}_{1}+\mathrm{x}_{2}, \mathrm{q}\right) \wedge \mathrm{B}\left(\mathrm{y}_{1}+\mathrm{y}_{2}, \mathrm{q}\right)=\mathrm{A}\left(\mathrm{x}_{2}+\mathrm{x}_{1}, \mathrm{q}\right) \wedge \mathrm{B}\left(\mathrm{y}_{2}+\mathrm{y}_{1}, \mathrm{q}\right)$

$=\mathrm{A} \times \mathrm{B}\left(\left(\mathrm{x}_{2}+\mathrm{x}_{1}, \mathrm{y}_{2}+\mathrm{y}_{1}\right), \mathrm{q}\right)=\mathrm{A} \times \mathrm{B}\left[\left(\mathrm{x}_{2}, \mathrm{y}_{2}\right)+\left(\mathrm{x}_{1}, \mathrm{y}_{1}\right), \mathrm{q}\right]$.

Therefore, $\mathrm{A} \times \mathrm{B}\left[\left(\mathrm{x}_{1}, \mathrm{y}_{1}\right)+\left(\mathrm{x}_{2}, \mathrm{y}_{2}\right), \mathrm{q}\right]=\mathrm{A} \times \mathrm{B}\left[\left(\mathrm{x}_{2}, \mathrm{y}_{2}\right)+\left(\mathrm{x}_{1}, \mathrm{y}_{1}\right), \mathrm{q}\right]$.

And, $A \times B\left[\left(x_{1}, y_{1}\right)\left(x_{2}, y_{2}\right), q\right]=A \times B\left(\left(x_{1} x_{2}, y_{1} y_{2}\right), q\right)$

$=A\left(x_{1} x_{2}, q\right) \wedge B\left(y_{1} y_{2}, q\right)=A\left(x_{2} x_{1}, q\right), B\left(y_{2} y_{1}, q\right)=$

$\mathrm{A} \times \mathrm{B}\left(\left(\mathrm{x}_{2} \mathrm{x}_{1}, \mathrm{y}_{2} \mathrm{y}_{1}\right), \mathrm{q}\right)=\mathrm{A} \times \mathrm{B}\left[\left(\mathrm{x}_{2}, \mathrm{y}_{2}\right)\left(\mathrm{x}_{1}, \mathrm{y}_{1}\right), \mathrm{q}\right]$.

Therefore, $\quad \mathrm{A} \times \mathrm{B}\left[\left(\mathrm{x}_{1}, \mathrm{y}_{1}\right)\left(\mathrm{x}_{2}, \mathrm{y}_{2}\right), \mathrm{q}\right]=\mathrm{A} \times \mathrm{B}\left[\left(\mathrm{x}_{2}, \mathrm{y}_{2}\right)\left(\mathrm{x}_{1}, \mathrm{y}_{1}\right), \mathrm{q}\right]$. Hence $A \times B$ is an $(Q, L)$-fuzzy normal subsemiring of $\mathrm{G} \times \mathrm{H}$.

\subsection{Theorem 4}

Let $\mathrm{A}$ be a fuzzy subset in a semiring $\mathrm{R}$ and $\mathrm{V}$ be the strongest (Q,L)-fuzzy relation on $\mathrm{R}$. Then $\mathrm{A}$ is an $(\mathrm{Q}, \mathrm{L})$-fuzzy normal subsemiring of $\mathrm{R}$ if and only if $\mathrm{V}$ is an (Q,L)-fuzzy normal subsemiring of $\mathrm{R} \times \mathrm{R}$.

Proof: Suppose that A is a (Q,L)-fuzzy normal subsemiring of $R$. Then for any $x=\left(x_{1}, x_{2}\right)$ and $y=\left(y_{1}, y_{2}\right)$ are in $R \times R$ and $q$ in $\mathrm{Q}$. Clearly $\mathrm{V}$ is a $(\mathrm{Q}, \mathrm{L})$-fuzzy subsemiring of $\mathrm{R} \times \mathrm{R}$. We have, $\mathrm{V}(\mathrm{x}+\mathrm{y}, \mathrm{q})=\mathrm{V}\left[\left(\mathrm{x}_{1}, \mathrm{x}_{2}\right)+\left(\mathrm{y}_{1}, \mathrm{y}_{2}\right), \mathrm{q}\right]=\mathrm{V}\left(\left(\mathrm{x}_{1}+\mathrm{y}_{1}, \mathrm{x}_{2}+\mathrm{y}_{2}\right), \mathrm{q}\right)$

$=\mathrm{A}\left(\left(\mathrm{x}_{1}+\mathrm{y}_{1}\right), \mathrm{q}\right) \wedge \mathrm{A}\left(\left(\mathrm{x}_{2}+\mathrm{y}_{2}\right), \mathrm{q}\right)=\mathrm{A}\left(\left(\mathrm{y}_{1}+\mathrm{x}_{1}\right), \mathrm{q}\right) \wedge \mathrm{A}\left(\left(\mathrm{y}_{2}+\mathrm{x}_{2}\right), \mathrm{q}\right)$

$=\mathrm{V}\left(\left(\mathrm{y}_{1}+\mathrm{x}_{1}, \mathrm{y}_{2}+\mathrm{x}_{2}\right), \mathrm{q}\right)=\mathrm{V}\left[\left(\mathrm{y}_{1}, \mathrm{y}_{2}\right)+\left(\mathrm{x}_{1}, \mathrm{x}_{2}\right), \mathrm{q}\right]=\mathrm{V}(\mathrm{y}+\mathrm{x}, \mathrm{q})$

Therefore, $\mathrm{V}(\mathrm{x}+\mathrm{y}, \mathrm{q})=\mathrm{V}(\mathrm{y}+\mathrm{x}, \mathrm{q})$, for all $\mathrm{x}$ and $\mathrm{y}$ in $\mathrm{R} \times \mathrm{R}$ and $\mathrm{q}$ in Q. We have, $V(x y, q)=V\left[\left(x_{1}, x_{2}\right)\left(y_{1}, y_{2}\right), q\right]=V\left(\left(x_{1} y_{1}, x_{2} y_{2}\right), q\right)$ $=\mathrm{A}\left(\left(\mathrm{x}_{1} \mathrm{y}_{1}\right), \mathrm{q}\right) \wedge \mathrm{A}\left(\left(\mathrm{x}_{2} \mathrm{y}_{2}\right), \mathrm{q}\right)=\mathrm{A}\left(\left(\mathrm{y}_{1} \mathrm{x}_{1}\right), \mathrm{q}\right) \wedge \mathrm{A}\left(\left(\mathrm{y}_{2} \mathrm{x}_{2}\right), \mathrm{q}\right)$

$=\mathrm{V}\left(\left(\mathrm{y}_{1} \mathrm{x}_{1}, \mathrm{y}_{2} \mathrm{x}_{2}\right), \mathrm{q}\right)=\mathrm{V}\left[\left(\mathrm{y}_{1}, \mathrm{y}_{2}\right)\left(\mathrm{x}_{1}, \mathrm{x}_{2}\right), \mathrm{q}\right]=\mathrm{V}(\mathrm{yx}, \mathrm{q})$

Therefore, $V(x y, q)=V(y x, q)$, for all $x$ and $y$ in $R \times R$ and $q$ in $Q$. This proves that $\mathrm{V}$ is a $(\mathrm{Q}, \mathrm{L})$-fuzzy normal subsemiring of $\mathrm{R} \times \mathrm{R}$. Conversely, assume that $\mathrm{V}$ is a $(\mathrm{Q}, \mathrm{L})$-fuzzy normal subsemiring of $\mathrm{R} \times \mathrm{R}$, then for any $\mathrm{x}=\left(\mathrm{x}_{1}, \mathrm{x}_{2}\right)$ and $\mathrm{y}=\left(\mathrm{y}_{1}, \mathrm{y}_{2}\right)$ are in $\mathrm{R} \times \mathrm{R}$, we have

$$
\mathrm{A}\left(\mathrm{x}_{1}+\mathrm{y}_{1}, \mathrm{q}\right) \wedge \mathrm{A}\left(\mathrm{x}_{2}+\mathrm{y}_{2}, \mathrm{q}\right)=\mathrm{V}\left(\left(\mathrm{x}_{1}+\mathrm{y}_{1}, \mathrm{x}_{2}+\mathrm{y}_{2}\right), \mathrm{q}\right)
$$

$=\mathrm{V}\left[\left(\mathrm{x}_{1}, \mathrm{x}_{2}\right)+\left(\mathrm{y}_{1}, \mathrm{y}_{2}\right), \mathrm{q}\right]=\mathrm{V}(\mathrm{x}+\mathrm{y}, \mathrm{q})=\mathrm{V}(\mathrm{y}+\mathrm{x}, \mathrm{q})$

$=\mathrm{V}\left[\left(\mathrm{y}_{1}, \mathrm{y}_{2}\right)+\left(\mathrm{x}_{1}, \mathrm{x}_{2}\right), \mathrm{q}\right]=\mathrm{V}\left(\left(\mathrm{y}_{1}+\mathrm{x}_{1}, \mathrm{y}_{2}+\mathrm{x}_{2}\right), \mathrm{q}\right)$

$=\mathrm{A}\left(\mathrm{y}_{1}+\mathrm{x}_{1}, \mathrm{q}\right) \wedge \mathrm{A}\left(\mathrm{y}_{2}+\mathrm{x}_{2}, \mathrm{q}\right)$. We get, $\mathrm{A}\left(\left(\mathrm{x}_{1}+\mathrm{y}_{1}\right), \mathrm{q}\right)=\mathrm{A}\left(\left(\mathrm{y}_{1}+\mathrm{x}_{1}\right), \mathrm{q}\right)$, for all $\mathrm{x}_{1}$ and $\mathrm{y}_{1}$ in $\mathrm{R}$ and $\mathrm{q}$ in $\mathrm{Q}$. And $\mathrm{A}\left(\mathrm{x}_{1} \mathrm{y}_{1}, \mathrm{q}\right) \wedge \mathrm{A}\left(\mathrm{x}_{2} \mathrm{y}_{2}, \mathrm{q}\right)=\mathrm{V}\left(\left(\mathrm{x}_{1} \mathrm{y}_{1}, \mathrm{x}_{2} \mathrm{y}_{2}\right), \mathrm{q}\right)=\mathrm{V}\left[\left(\mathrm{x}_{1}, \mathrm{x}_{2}\right)\left(\mathrm{y}_{1}, \mathrm{y}_{2}\right), \mathrm{q}\right]$ $=\mathrm{V}(\mathrm{xy}, \mathrm{q})=\mathrm{V}(\mathrm{yx}, \mathrm{q})=\mathrm{V}\left[\left(\mathrm{y}_{1}, \mathrm{y}_{2}\right)\left(\mathrm{x}_{1}, \mathrm{x}_{2}\right), \mathrm{q}\right]=\mathrm{V}\left(\left(\mathrm{y}_{1} \mathrm{x}_{1}, \mathrm{y}_{2} \mathrm{x}_{2}\right), \mathrm{q}\right)$ $=A\left(y_{1} x_{1}, q\right) \wedge A\left(y_{2} x_{2}, q\right)$. We get, $A\left(\left(x_{1} y_{1}\right), q\right)=A\left(\left(y_{1} x_{1}\right), q\right)$, for all $x_{1}$ and $y_{1}$ in $R$ and $q$ in $Q$. Hence $A$ is a $(Q, L)$-fuzzy normal 
subsemiring of $\mathrm{R}$.

\subsection{Theorem 5}

Let $(\mathrm{R},+,$.$) and \left(\mathrm{R}^{\prime},+,.\right)$ be any two semirings and $\mathrm{Q}$ be a non-empty set. The homomorphic image of an $(\mathrm{Q}, \mathrm{L})$-fuzzy normal subsemiring of $\mathrm{R}$ is an (Q,L)-fuzzy normal subsemiring of $\mathrm{R}^{\prime}$.

Proof: Let $(\mathrm{R},+,$.$) and \left(\mathrm{R}^{\prime},+,.\right)$ be any two semirings $\mathrm{Q}$ be a non-empty set and $\mathrm{f}: \mathrm{R} \rightarrow \mathrm{R}$ 'be a homomorphism. Then, $f(x+y)=f(x)+f(y)$ and $f(x y)=f(x) f(y)$, for all $x$ and $y$ in $R$. Let $\mathrm{V}=\mathrm{f}(\mathrm{A})$, where $\mathrm{A}$ is an $(\mathrm{Q}, \mathrm{L})$-fuzzy normal subsemiring of a semiring $\mathrm{R}$. We have to prove that $\mathrm{V}$ is an $(\mathrm{Q}, \mathrm{L})$-fuzzy normal subsemiring of a semiring $R^{\prime}$. Now, for $f(x), f(y)$ in $R^{\prime}$, clearly $\mathrm{V}$ is an (Q,L)-fuzzy subsemiring of a semiring $\mathrm{R}^{\prime}$, since $\mathrm{A}$ is an (Q,L)-fuzzy subsemiring of a semiring $R$. Now, $\mathrm{V}(\mathrm{f}(\mathrm{x})+\mathrm{f}(\mathrm{y}), \mathrm{q})=\mathrm{V}(\mathrm{f}(\mathrm{x}+\mathrm{y}), \mathrm{q}) \geq \mathrm{A}(\mathrm{x}+\mathrm{y}, \mathrm{q})=\mathrm{A}(\mathrm{y}+\mathrm{x}, \mathrm{q}) \leq \mathrm{V}(\mathrm{f}(\mathrm{y}+\mathrm{x}), \mathrm{q})$ $=\mathrm{V}(\mathrm{f}(\mathrm{y})+\mathrm{f}(\mathrm{x}), \mathrm{q})$, which implies that $\mathrm{V}(\mathrm{f}(\mathrm{x})+\mathrm{f}(\mathrm{y}), \mathrm{q})=$ $\mathrm{V}\left(\mathrm{f}(\mathrm{y})+(\mathrm{f}(\mathrm{x}), \mathrm{q})\right.$, for all $\mathrm{f}(\mathrm{x})$ and $\mathrm{f}(\mathrm{y})$ in $\mathrm{R}^{\prime}$. Again, $\mathrm{V}(\mathrm{f}(\mathrm{x}) \mathrm{f}(\mathrm{y}), \mathrm{q})=\mathrm{V}(\mathrm{f}(\mathrm{xy}), \mathrm{q}) \geq \mathrm{A}(\mathrm{xy}, \mathrm{q})=\mathrm{A}(\mathrm{yx}, \mathrm{q}) \leq \mathrm{V}(\mathrm{f}(\mathrm{yx}), \mathrm{q})$

$=V(f(y) f(x), q)$, which implies that $V(f(x) f(y), q)=V(f(y) f(x), q)$, for all $f(x)$ and $f(y)$ in $R^{\prime}$. Hence $V$ is an $(Q, L)$-fuzzy normal subsemiring of a semiring $\mathrm{R}^{\mathrm{l}}$.

\subsection{Theorem 6}

Let $(\mathrm{R},+,$.$) and \left(\mathrm{R}^{\prime},+,.\right)$ be any two semirings and $\mathrm{Q}$ be a non-empty set. The homomorphic preimage of an (Q,L)-fuzzy normal subsemiring of $\mathrm{R}^{\prime}$ is an (Q,L)-fuzzy normal subsemiring of $\mathrm{R}$.

Proof: Let $(\mathrm{R},+,$.$) and \left(\mathrm{R}^{\prime},+,.\right)$ be any two semirings and $\mathrm{Q}$ be a non-empty set and $\mathrm{f}: \mathrm{R} \rightarrow \mathrm{R}^{\mathrm{\prime}}$ be a homomorphism. Then, $f(x+y)=f(x)+f(y)$ and $f(x y)=f(x) f(y)$, for all $x$ and $y$ in $R$. Let $V=f(A)$, where $V$ is an $(Q, L)$-fuzzy normal subsemiring of a semiring $R$ !. We have to prove that $A$ is an $(Q, L)$-fuzzy normal subsemirring of a semiring $\mathrm{R}$. Let $\mathrm{x}$ and $\mathrm{y}$ in $\mathrm{R}$. Then, clearly $A$ is an (Q,L)-fuzzy subsemiring of a semiring $R$, since $\mathrm{V}$ is an (Q,L)-fuzzy subsemiring of a semiring $\mathrm{R}$ !. Now, $\mathrm{A}(\mathrm{x}+\mathrm{y}, \mathrm{q})=\mathrm{V}(\mathrm{f}(\mathrm{x}+\mathrm{y}), \mathrm{q})=\mathrm{V}(\mathrm{f}(\mathrm{x})+\mathrm{f}(\mathrm{y}), \mathrm{q})=\mathrm{V}(\mathrm{f}(\mathrm{y})+\mathrm{f}(\mathrm{x}), \mathrm{q})=$ $\mathrm{V}(\mathrm{f}(\mathrm{y}+\mathrm{x}), \mathrm{q})=\mathrm{A}(\mathrm{y}+\mathrm{x}, \mathrm{q})$, which implies that $A(x+y, q)=A(y+x, q)$, for all $x$ and $y$ in $R$ and $q$ in $Q$. Again, $\mathrm{A}(\mathrm{xy}, \mathrm{q})=\mathrm{V}(\mathrm{f}(\mathrm{xy}), \mathrm{q})=\mathrm{V}(\mathrm{f}(\mathrm{x}) \mathrm{f}(\mathrm{y}), \mathrm{q})=\mathrm{V}(\mathrm{f}(\mathrm{y}) \mathrm{f}(\mathrm{x}), \mathrm{q})=\mathrm{V}(\mathrm{f}(\mathrm{yx}), \mathrm{q})=$ $\mathrm{A}(\mathrm{yx}, \mathrm{q})$, which implies that $\mathrm{A}(\mathrm{xy}, \mathrm{q})=\mathrm{A}(\mathrm{yx}, \mathrm{q})$, for all $\mathrm{x}$ and $\mathrm{y}$ in $\mathrm{R}$ and $\mathrm{q}$ in $\mathrm{Q}$. Hence $\mathrm{A}$ is an $(\mathrm{Q}, \mathrm{L})$-fuzzy normal subsemiring of a semiring $\mathrm{R}$.

\subsection{Theorem 7}

Let $(\mathrm{R},+,$.$) and \left(\mathrm{R}^{\prime},+,.\right)$ be any two semirings and $\mathrm{Q}$ be a non-empty set. The anti-homomorphic image of an $(\mathrm{Q}$, $\mathrm{L})$-fuzzy normal subsemiring of $\mathrm{R}$ is an $(\mathrm{Q}, \mathrm{L})$-fuzzy normal subsemiring of $\mathrm{R}^{\prime}$.

Proof: Let $(\mathrm{R},+,$.$) and \left(\mathrm{R}^{\prime},+,.\right)$ be any two semirings and $\mathrm{Q}$ be a non-empty set and $\mathrm{f}: \mathrm{R} \rightarrow \mathrm{R}^{\prime}$ be an anti-homomorphism. Then, $f(x+y)=f(y)+f(x)$ and $f(x y)=f(y) f(x)$, for all $x$ and $y$ in $R$ Let $V=f(A)$, where $A$ is an $(Q, L)$-fuzzy normal subsemiring of a semiring $\mathrm{R}$. We have to prove that $\mathrm{V}$ is an $(\mathrm{Q}, \mathrm{L})$-fuzzy normal subsemiring of a semiring $R^{\prime}$. Now, for $f(x)$ and $f(y)$ in $R^{\prime}$, clearly $V$ is an $(Q, L)$-fuzzy subsemiring of a semiring $R^{\prime}$, since $A$ is an $(\mathrm{Q}, \mathrm{L})$-fuzzy subsemiring of a semiring $\mathrm{R}$. Now, $\mathrm{V}(\mathrm{f}(\mathrm{x})+\mathrm{f}(\mathrm{y}), \mathrm{q})=\mathrm{V}(\mathrm{f}(\mathrm{y}+\mathrm{x}), \mathrm{q}) \geq \mathrm{A}(\mathrm{y}+\mathrm{x}, \mathrm{q})=\mathrm{A}(\mathrm{x}+\mathrm{y}, \mathrm{q}) \leq \mathrm{V}(\mathrm{f}(\mathrm{x}+\mathrm{y}), \mathrm{q})$
$=\mathrm{V}(\mathrm{f}(\mathrm{y})+\mathrm{f}(\mathrm{x}), \mathrm{q}), \quad$ which $\quad$ implies that $\mathrm{V}(\mathrm{f}(\mathrm{x})+\mathrm{f}(\mathrm{y}), \mathrm{q})=\mathrm{V}(\mathrm{f}(\mathrm{y})+\mathrm{f}(\mathrm{x}), \mathrm{q})$, for all $\mathrm{f}(\mathrm{x})$ and $\mathrm{f}(\mathrm{y})$ in $\mathrm{R}^{\prime}$. Again, $V(f(x) f(y), q)=V(f(y x), q) \geq A(y x, q)=A(x y, q) \leq V(f(x y), q)$ $=V(f(y) f(x), q)$, which implies that $V(f(x) f(y), q)=V(f(y) f(x), q)$, for all $f(x)$ and $f(y)$ in $R^{\prime}$. Hence $V$ is an $(Q, L)$-fuzzy normal subsemiring of a semiring $\mathrm{R}$.

\subsection{Theorem 8}

Let $(\mathrm{R},+,$.$) and \left(\mathrm{R}^{\prime},+,.\right)$ be any two semirings and $\mathrm{Q}$ be a non-empty set. The anti-homomorphic preimage of an (Q,L)-fuzzy normal subsemiring of $\mathrm{R}^{\prime}$ is an (Q,L)-fuzzy normal subsemiring of $\mathrm{R}$.

Proof: Let $(\mathrm{R},+,$.$) and \left(\mathrm{R}^{\prime},+,.\right)$ be any two semirings and $\mathrm{Q}$ be a non-empty set and $\mathrm{f}: \mathrm{R} \rightarrow \mathrm{R}^{\prime}$ be an anti-homomorphism. Then, $f(x+y)=f(y)+f(x)$ and $f(x y)=f(y) f(x)$, for all $x$ and $y$ in R.Let $\mathrm{V}=\mathrm{f}(\mathrm{A})$, where $\mathrm{V}$ is an $(\mathrm{Q}, \mathrm{L})$-fuzzy normal subsemiring of a semiring $R^{\prime}$. We have to prove that $A$ is an $(Q, L)$-fuzzy normal subsemiring of a semiring $R$. Let $x$ and $y$ in $R$, then clearly $A$ is an $(Q, L)$-fuzzy subsemiring of a semiring $R$, since $\mathrm{V}$ is an $(\mathrm{Q}, \mathrm{L})$-fuzzy subsemiring of a semiring $\mathrm{R}^{\prime}$. Now, $\mathrm{A}(\mathrm{x}+$ $\mathrm{y}, \mathrm{q})=\mathrm{V}(\mathrm{f}(\mathrm{x}+\mathrm{y}), \mathrm{q})=\mathrm{V}(\mathrm{f}(\mathrm{y})+\mathrm{f}(\mathrm{x}), \mathrm{q})=\mathrm{V}(\mathrm{f}(\mathrm{x})+\mathrm{f}(\mathrm{y}), \mathrm{q})=\mathrm{V}(\mathrm{f}(\mathrm{y}+\mathrm{x}), \mathrm{q})$ $=\mathrm{A}(\mathrm{y}+\mathrm{x}, \mathrm{q})$, which implies that $\mathrm{A}(\mathrm{x}+\mathrm{y}, \mathrm{q})=\mathrm{A}(\mathrm{y}+\mathrm{x}, \mathrm{q})$, for all $\mathrm{x}$ and $\mathrm{y}$ in $\mathrm{R}$ and $\mathrm{q}$ in $\mathrm{Q}$. Again, $A(x y, q)=V(f(x y), q)=V(f(y) f(x), q)=V(f(x) f(y), q)=V(f(y x), q)=$ $\mathrm{A}(\mathrm{yx}, \mathrm{q})$, which implies that $\mathrm{A}(\mathrm{xy}, \mathrm{q})=\mathrm{A}(\mathrm{yx}, \mathrm{q})$, for all $\mathrm{x}$ and $\mathrm{y}$ in $\mathrm{R}$ and $\mathrm{q}$ in $\mathrm{Q}$. Hence $\mathrm{A}$ is an $(\mathrm{Q}, \mathrm{L})$-fuzzy normal subsemiring of a semiring $\mathrm{R}$.

\subsection{Theorem 9}

Let $\mathrm{A}$ be an (Q, L)-fuzzy normal subsemiring of a semiring $(\mathrm{R},+,$.$) , then the pseudo (\mathrm{Q}, \mathrm{L})$-fuzzy coset $(\mathrm{aA})^{\mathrm{p}}$ is an $(\mathrm{Q}$, $\mathrm{L}$ )-fuzzy normal subsemiring of a semiring $\mathrm{R}$, for a in Rand $\mathrm{q}$ in Q.

Proof: Let A be an (Q, L)-fuzzy normal subsemiring of a semiring $\mathrm{R}$. For every $\mathrm{x}$ and $\mathrm{y}$ in Rand $\mathrm{q}$ in $\mathrm{Q}$, we have, $\left((\mathrm{aA})^{\mathrm{p}}\right)(\mathrm{x}+\mathrm{y})=\mathrm{p}(\mathrm{a}) \mathrm{A}(\mathrm{x}+\mathrm{y}) \geq \mathrm{p}(\mathrm{a})\{(\mathrm{A}(\mathrm{x}) \wedge \mathrm{A}(\mathrm{y})\}=$ $\{\mathrm{p}(\mathrm{a}) \mathrm{A}(\mathrm{x}) \wedge \mathrm{p}(\mathrm{a}) \mathrm{A}(\mathrm{y})\}=\left\{\left((\mathrm{aA})^{\mathrm{p}}\right)(\mathrm{x}) \wedge\left((\mathrm{aA})^{\mathrm{p}}\right)(\mathrm{y})\right\}$. Therefore, $\left((\mathrm{aA})^{\mathrm{p}}\right)(\mathrm{x}+\mathrm{y})=\left\{\left((\mathrm{aA})^{\mathrm{p}}\right)(\mathrm{x}) \wedge\left((\mathrm{aA})^{\mathrm{p}}\right)(\mathrm{y})\right\}$.

Now, $\quad\left((\mathrm{aA})^{\mathrm{p}}\right)(\mathrm{xy})=\mathrm{p}(\mathrm{a}) \mathrm{A}(\mathrm{xy}) \geq \mathrm{p}(\mathrm{a})\{\mathrm{A}(\mathrm{x}) \wedge \mathrm{A}(\mathrm{y})\} \quad=$ $\{\mathrm{p}(\mathrm{a}) \mathrm{A}(\mathrm{x}) \wedge \mathrm{p}(\mathrm{a}) \mathrm{A}(\mathrm{y})\}=\left\{\left((\mathrm{aA})^{\mathrm{p}}\right)(\mathrm{x}) \wedge\left((\mathrm{aA})^{\mathrm{p}}\right)(\mathrm{y})\right\}$.

Therefore, $\left((\mathrm{aA})^{\mathrm{p}}\right)(\mathrm{xy})=\left\{\left((\mathrm{aA})^{\mathrm{p}}\right)(\mathrm{x}) \wedge\left((\mathrm{aA})^{\mathrm{p}}\right)(\mathrm{y})\right\}$. Hence $(\mathrm{aA})^{\mathrm{p}}$ is an $(\mathrm{Q}, \mathrm{L})$-fuzzy normal subsemiring of a semiring $\mathrm{R}$.

\subsection{Theorem 10}

Let $A$ and $B$ be (Q,L)-fuzzy subsets of the sets $R$ and $H$ respectively, and let $\alpha$ in L. Then $(A \times B)_{\alpha}=A_{\alpha} \times B_{\alpha}$.

Proof: Let $\alpha$ in L. Let $(\mathrm{x}, \mathrm{y})$ be in $(\mathrm{A} \times \mathrm{B})_{\alpha}$ if and only if $\mathrm{A} \times \mathrm{B}((\mathrm{x}, \mathrm{y}), \mathrm{q}) \geq \alpha$

if and only if $\{\mathrm{A}(\mathrm{x}, \mathrm{q}) \wedge \mathrm{B}(\mathrm{x}, \mathrm{q})\} \geq \alpha$

if and only if $A(x, q) \geq \alpha$ and $B(x, q) \geq \alpha$

if and only if $\mathrm{x} \epsilon \mathrm{A}_{\alpha}$ and $\mathrm{y} \epsilon \mathrm{B}_{\alpha}$

if and only if $(\mathrm{x}, \mathrm{y}) \in \mathrm{A}_{\alpha} \times \mathrm{B}_{\alpha}$.

Therefore, $(\mathrm{A} \times \mathrm{B})_{\alpha}=\mathrm{A}_{\alpha} \times \mathrm{B}_{\alpha}$.

\subsection{Theorem 11}

Let $A$ be a (Q,L)-fuzzy normal subsemiring of a semiring $R$. If $A(x, q)<A(y, q)$, for some $x$ and $y$ in $R$ and $q$ in $Q$, then $\mathrm{A}(\mathrm{x}+\mathrm{y}, \mathrm{q})=\mathrm{A}(\mathrm{x}, \mathrm{q})=\mathrm{A}(\mathrm{y}+\mathrm{x}, \mathrm{q})$, for some $\mathrm{x}$ and $\mathrm{y}$ in $\mathrm{R}$ and $\mathrm{q}$ in $\mathrm{Q}$. 
Proof: It is trivial.

\subsection{Theorem 12}

Let $A$ be a (Q,L)-fuzzy normal subsemiring of a semiring $R$. If $\mathrm{A}(\mathrm{x}, \mathrm{q})>\mathrm{A}(\mathrm{y}, \mathrm{q})$, for some $\mathrm{x}$ and $\mathrm{y}$ in $\mathrm{R}$ and $\mathrm{q}$ in $\mathrm{Q}$, then $\mathrm{A}(\mathrm{x}+\mathrm{y}, \mathrm{q})=\mathrm{A}(\mathrm{y}, \mathrm{q})=\mathrm{A}(\mathrm{y}+\mathrm{x}, \mathrm{q})$, for some $\mathrm{x}$ and $\mathrm{y}$ in $\mathrm{R}$ and $\mathrm{q}$ in $\mathrm{Q}$.

Proof: It is trivial.

\subsection{Theorem 13}

Let $A$ be a $(\mathrm{Q}, \mathrm{L})$-fuzzy normal subsemiring of a semiring $\mathrm{R}$ such that $\operatorname{Im} A=\{\alpha\}$, where $\alpha$ in L. If $A=B \bigcup C$, where $B$ and $\mathrm{C}$ are $(\mathrm{Q}, \mathrm{L})$-fuzzy normal subsemiring of a semiring $\mathrm{R}$, then either $\mathrm{B} \subseteq \mathrm{C}$ or $\mathrm{C} \subseteq \mathrm{B}$.

Proof: It is trivial.

\section{In the Following Theorem is the Composition Operation of Functions}

\subsection{Theorem 1}

Let $\mathrm{A}$ be an $(\mathrm{Q}, \mathrm{L})$-fuzzy normal subsemiring of a semiring $\mathrm{H}$ and $\mathrm{f}$ is an isomorphism from a semiring $\mathrm{R}$ onto $\mathrm{H}$. Then $\mathrm{A} \circ \mathrm{f}$ is an (Q,L)-fuzzy normal subsemiring of the semiring $\mathrm{R}$.

Proof: Let $\mathrm{x}$ and $\mathrm{y}$ in $\mathrm{R}$ and $\mathrm{A}$ be an (Q,L)-fuzzy normal subsemiring of a semiring $H$. Then clearly $A \circ f$ is an $(\mathrm{Q}, \mathrm{L})$-fuzzy subsemiring of a semiring R. Now, $(\mathrm{A} \circ \mathrm{f})(\mathrm{x}+\mathrm{y}, \mathrm{q})$ $=A(f(x+y), q)=A(f(x)+f(y), q)=A(f(y)+f(x), q)=A(f(y+x), q)$ $=(A \circ f)(y+x, q)$, which implies that $(A \circ f)(x+y, q)=(A \circ f)(y+x, q)$, for all $x$ and $y$ in $R$ and $q$ in $Q$. And, $(A \circ f)(x y, q)=$ $A(f(x y), q)=A(f(x) f(y), q)=A(f(y) f(x), q)=A(f(y x), q)=$

$(A \circ f)(y x, q)$, which implies that $(A \circ f)(x y, q)=(A \circ f)(y x, q)$, for all $x$ and $y$ in $R$ and $q$ in $Q$. Hence $A \circ f$ is an $(Q, L)$-fuzzy normal subsemiring of a semiring $\mathrm{R}$.

\subsection{Theorem 2}

Let $\mathrm{A}$ be an (Q,L)-fuzzy normal subsemiring of a semiring $\mathrm{H}$ and $\mathrm{f}$ is an anti-isomorphism from a semiring $\mathrm{R}$ onto $\mathrm{H}$. Then $A \circ f$ is an $(Q, L)$-fuzzy normal subsemiring of the semiring R.

Proof: Let $\mathrm{x}$ and $\mathrm{y}$ in $\mathrm{R}$ and $\mathrm{A}$ be an (Q,L)-fuzzy normal subsemiring of a semiring $H$. Then clearly $A \circ f$ is an $(\mathrm{Q}, \mathrm{L})$-fuzzy subsemiring of a semiring $\mathrm{R}$. Now, $(\mathrm{A} \circ \mathrm{f})(\mathrm{x}+\mathrm{y}, \mathrm{q})=$ $\mathrm{A}(\mathrm{f}(\mathrm{x}+\mathrm{y}), \mathrm{q})=\mathrm{A}(\mathrm{f}(\mathrm{y})+\mathrm{f}(\mathrm{x}), \mathrm{q})=\mathrm{A}(\mathrm{f}(\mathrm{x})+\mathrm{f}(\mathrm{y}), \mathrm{q})=\mathrm{A}(\mathrm{f}(\mathrm{y}+\mathrm{x}), \mathrm{q})=$ $(A \circ f)(y+x, q)$, which implies that $(A \circ f)(x+y, q)=(A \circ f)(y+x, q)$, for all $\mathrm{x}$ and $\mathrm{y}$ in $\mathrm{R}$ and $\mathrm{q}$ in $\mathrm{Q}$. And, $(\mathrm{A} \circ \mathrm{f})(\mathrm{xy}, \mathrm{q})=$ $\mathrm{A}(\mathrm{f}(\mathrm{xy}), \mathrm{q})=\mathrm{A}(\mathrm{f}(\mathrm{y}) \mathrm{f}(\mathrm{x}), \mathrm{q})=\mathrm{A}(\mathrm{f}(\mathrm{x}) \mathrm{f}(\mathrm{y}), \mathrm{q})=\mathrm{A}(\mathrm{f}(\mathrm{yx}), \mathrm{q})=$ $(A \circ f)(y x, q)$, which implies that $(A \circ f)(x y, q)=(A \circ f)(y x, q)$, for all $x$ and $y$ in $R$ and $q$ in $Q$. Hence $A \circ f$ is an $(Q, L)$-fuzzy normal subsemiring of a semiring $\mathrm{R}$.

\section{Acknowledgements}

The authors would like to be thankful to the anonymous reviewers for their valuable suggestions.

\section{References}

[1] Azriel Rosenfeld, Fuzzy Groups, Journal of mathematical analysis and applications, 35, 512-517 (1971).

[2] Anthony. J. M. and Sherwood. H, Fuzzy groups Redefined, Journal of mathematical analysis and applications, 69,124-130 (1979).

[3] Asok Kumer Ray, On product of fuzzy subgroups, fuzzy sets and sysrems, 105, 181-183 (1999).

[4] Biswas. R, Fuzzy subgroups and Anti-fuzzy subgroups, Fuzzy sets and systems, 35,121-124 (1990).

[5] Mustafa Akgul, Some properties of fuzzy groups, Journal of mathematical analysis and applications, 133, 93-100 (1988).

[6] Mohamed Asaad, Groups and fuzzy subgroups, fuzzy sets and systems (1991), North-Holland.

[7] Palaniappan. N \& Arjunan. K, Operation on fuzzy and anti fuzzy ideals, Antartica J. Math., 4(1) (2007), 59-64.

[8] Prabir Bhattacharya, Fuzzy Subgroups: Some Characterizations, Journal of Mathematical Analysis and Applications, 128, 241-252 (1987).

[9] Rajesh Kumar, Fuzzy Algebra, Volume 1, University of Delhi Publication Division, July -1993.

[10] Salah Abou-Zaid, On generalized characteristic fuzzy subgroups of a finite group, fuzzy sets and systems, 235-241 (1991).

[11] Sivaramakrishna das. P, Fuzzy groups and level subgroups, Journal of Mathematical Analysis and Applications, 84, 264-269 (1981).

[12] Solairaju. A and Nagarajan. R, A New Structure and Construction of Q-Fuzzy Groups, Advances in fuzzy mathematics, Volume 4, Number 1 (2009), 23-29.

[13] Tang J, Zhang X (2001). Product Operations in the Category of L-fuzzy groups. J. Fuzzy Math., 9:1-10.

[14] Vasantha kandasamy. W. B, Smarandache fuzzy algebra, American research press, Rehoboth -2003.

[15] Zadeh. L. A., Fuzzy sets , Information and control ,Vol.8, 338-353 (1965). 